\title{
The Park of Renewable Energy geoethical project
}

\author{
Patrizia Sibi ${ }^{1, \star}$, Mario Valletta ${ }^{2}$ \\ ${ }^{1}$ Università di Viterbo, Dipartimento di Ecologia e Scienze Biologiche (DEB), Centro di Educazione Ambientale, Viterbo, Italy \\ ${ }^{2}$ Associazione Italiana di Geologia e Turismo, Bologna, Italy
}

\author{
Article history \\ Received January 7, 2012; accepted March 23, 2012. \\ Subject classification: \\ Sustainable community, Renewable energy, Energy producers, Social participation, Green ethics.
}

\begin{abstract}
The Park of Renewable Energy is an environmental technology park in the middle of Italy that has an innovative integrated system for the production of renewable energy. Recently, the Park launched a public invitation: to become part of a great widespread community for the production of renewable energy, and to promote energy conservation and a sustainable lifestyle. This empowerment process that turns consumers into energy producers - and also into those who convey the culture of sustainability - might, over time, give life to a community that actually lives according to the geoethical principles of biosustainability. The route for the identification and dissemination of the Park of Renewable Energy community is an interesting example of the generative process, whereby rather than doggedly pursuing a predetermined objective, such as a model to be implemented, the actors involved, "look for directions and values that are inherent in the means available" [Bateson 2000], including communication networks and methodologies of social participation. The community components focus their attention on the action and relationship effects, rather than on ways to reach a predefined goal. In this perspective, the Park of Renewable Energy experience aims to become an interesting object of observation and reflection for its green ethics. This ecological approach promises unexpected new creations: there is a chance we will at last see the birth of a sustainable form of social organization adapted to the human community.
\end{abstract}

\section{Introduction:}

\section{towards a new ecologically based ethics}

"We cannot separate the human being from his life environment, and therefore we cannot change one without changing the other, transform the world without changing ourselves" [Bateson 2000].

If today "changing the world" means, first of all, the building of sustainable communities in which the lifestyle is in harmony with the natural vital processes, this goal requires the modification of our conceptions and behavior. In the first instance, it is necessary to change our bad habits, to think and act exclusively in terms of personal usefulness, without appraising the social and environmental cost, in anti-ecological terms.
The geosciences describe the complex natural systems, and reveal the organizational and conservation principles that regulate these systems. So they show us the fundamental principles of an ecological life style: to cooperate with Nature's ability to sustain life and preserve natural resources. The geoethical approach to a responsible and harmonious relationship between science and society leads the scientific disciplines, and especially technology and the exact sciences, to critical thoughts on the moral, social and cultural aspects of research, scientific communication and the popularization of science. Geoethics adopts a hermeneutic and critical type of reasoning, typical of the Earth sciences, and applies this to the topics of social responsibility and sustainability.

The debate on sustainability highlights the interpretative nature of knowledge, and has to constantly relate 'facts' and values, and epistemic and ethical aspects, to support a critical and dynamic type of thinking about environmental complexity. From this point of view, the question of human responsibility takes on an ecological dimension, as the inner process of knowledge itself. The practice of reasoning for relationships and interactions, to combine logical procedures, and to modify assumptions and theoretical aspects that deal with the issue of the man-planet relationship, encourages the exercise of 'deep questioning' towards ontological, ethical and social ideas [Morin 1999]. The human practice of 'making sense' of actions is based on these ideas. As a consequence, geoethics lays the foundations for an ethics that is oriented around ecological principles.

Also, today, the complexity of ecological and social issues and the unpredictable consequences of the 'technological doing' [Galimberti 2000] make it necessary to reassess the ethics from an ecological point of view.

Then, from the theoretic and operational points of view, geoethics appears to provide the guidelines for a new ecologically based ethics, where moral rules take shape through social participation, cultural interchange, and critical debate on the sustainability of human, and even nonhuman, life on our Planet. 


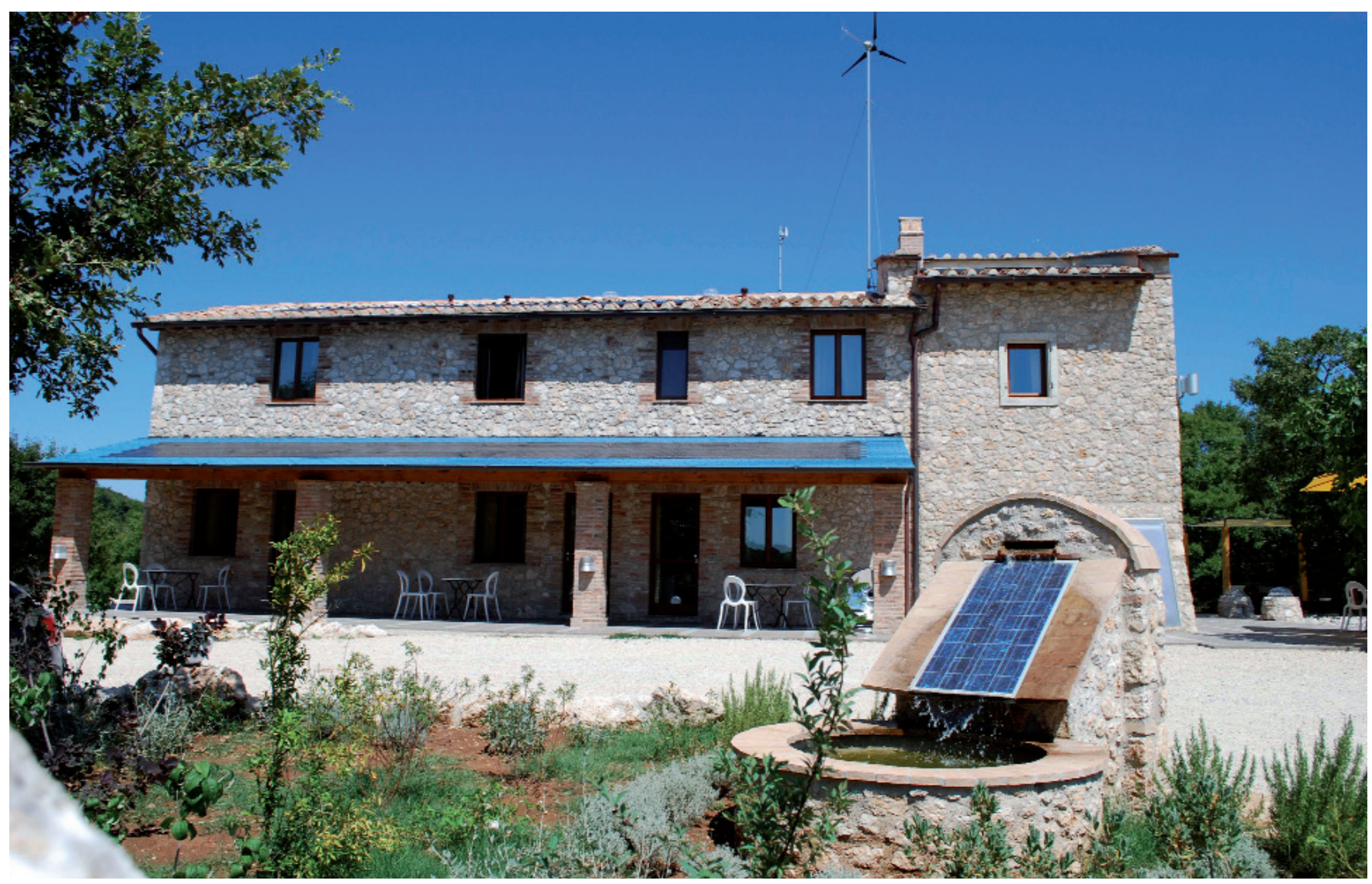

The promoters of the Park of Renewable Energy were inspired by these theoretical and operational principles, and today these same principles are the foundations of the Park community.

\section{The Park of Renewable Energy:} an interesting example of eco-sustainability

The Park of Renewable Energy is located in Umbria, in the middle of Italy, near Narni, 575 m a.s.l., inside an interesting area in terms of environmental and geological aspects. The Park lies in a rural area, far from factories and from industrial agriculture, inside a site of Community interest, in 6,000 hectares of woods, on a hilltop, where the sun and wind never fail.

The Narni territory within which the Park lies occupies part of the central sector of a large ridge that shows the classical orientation of the Apennines. Engraved by the course of River Nera, it extends from Mount Croce di Serra (municipality of Guardea) towards the northwest, and almost to the mountains of the Sabina territory towards the southeast. The peculiarity of this structural element is the presence of sediments of the Umbria-Marche succession, beginning from the Dolomites of the upper Triassic, to the marly-arenaceous formations of the middle Miocene. The limestone massif constitutes the widest element of this succession, and it is characterized by karst phenomena, particularly in the area of Mount Arnata, to the northwest of Narni. This formation is home to a large circulation of underground water, to which River Stifone is connected, with its capacity of 12.000 litres per second.

The Park of Renewable Energy was founded in 1999 by a few people with strong environmental awareness. Today, they are still living inside the Park. Without any public financing, the founders purchased the abandoned ground in the 1960's. They then began the restructuring of the 'ruins', giving life to a true process of recovery of the rural area. This has been possible through the integration of ancient practices and modern technological solutions.

Today the Park is an environmental technology park, with innovative integrated systems for the production of renewable energy (Figure 1). Since the beginning, the intention of the promoters was to spread the sustainability principles, and their quality of life and respect for the social and natural environment has characterized the park as a laboratory of environmental education, above all for students.

The buildings include an 'eco-hotel', with a zero-km restaurant and a zero-energy house equipped with solar panels, photovoltaic panels, wind generators, geothermal engines, and sophisticated systems for gray water recovery and for recycling of organic waste (Figures 2, 3, 4).

These systems are used both for the farm activities and for educational experiences for the visitors to the center (Figure 5). The site is totally independent from any supply network, including for the water supply. This makes it an interesting example of eco-sustainability.

Moreover, the territory of the Park has an added value. The characteristics of the natural environment and 

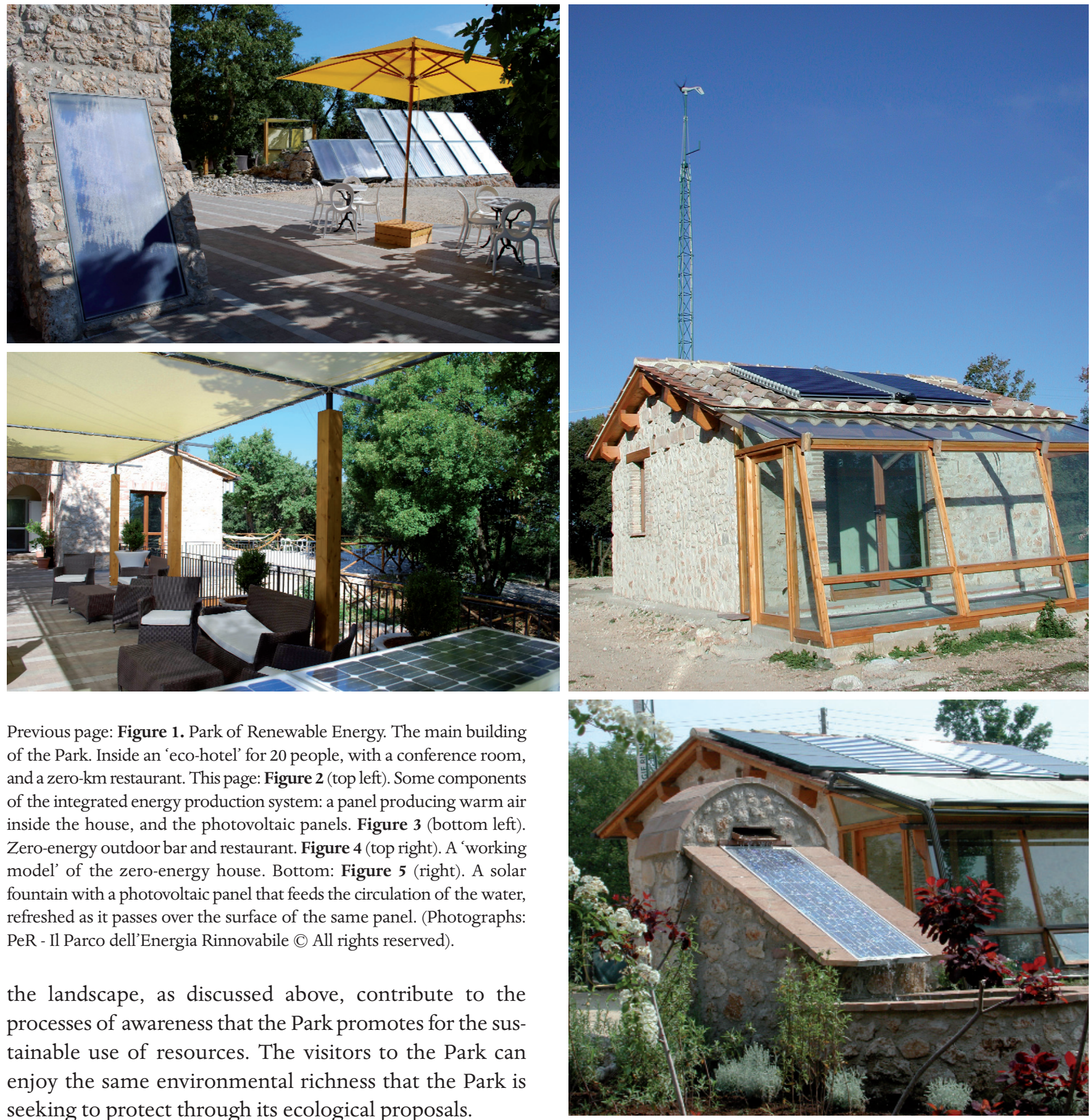

Previous page: Figure 1. Park of Renewable Energy. The main building of the Park. Inside an 'eco-hotel' for 20 people, with a conference room, and a zero-km restaurant. This page: Figure 2 (top left). Some components of the integrated energy production system: a panel producing warm air inside the house, and the photovoltaic panels. Figure 3 (bottom left). Zero-energy outdoor bar and restaurant. Figure 4 (top right). A 'working model' of the zero-energy house. Bottom: Figure 5 (right). A solar fountain with a photovoltaic panel that feeds the circulation of the water, refreshed as it passes over the surface of the same panel. (Photographs: PeR - Il Parco dell'Energia Rinnovabile (C) All rights reserved).

the landscape, as discussed above, contribute to the processes of awareness that the Park promotes for the sustainable use of resources. The visitors to the Park can enjoy the same environmental richness that the Park is seeking to protect through its ecological proposals.

\section{The Park of Renewable Energy}

\section{and the 'project' of a participatory social economy}

Over the last year, the Park has launched a public invitation. It has become part of a great widespread community for the production of renewable energy, and for the promotion of energy conservation and a sustainable lifestyle.

Today, about 100 people have accepted the invitation, and an association called Naturalife has been formed. Naturalife was constituted in November 2011 by 62 founders, with an investment of only $€ 50$ each. Naturalife membership comes with the following advantages:

- complete ownership of a share in the Park (it is not possible to purchase more than a single share);

- technical advice on zero-impact energy solutions;

- membership of the buying group known as Energy Technologies;

- lodging in the Park with convenient prices, according to the formula of a 'perfect price'.

The project started in May 2011, when the promoters

wrote a letter to Noam Chomsky, the famous American linguist, philosopher and communications theorist. They explained to him the idea of an experiment in democracy and of a participatory social economy. The appreciation and encouragement in Chomsky's reaction turned the idea into a real proposal.

Today, the Park is not only a technological experimental center on renewable energy, especially solar and wind power, it is also an opportunity for everyone to take 
part in a social experiment of a participatory economy. The number of Naturalife members is increasing continually, and many of them even live very far from the Park. So they rarely meet each other, but they pursue and share the same goals through virtual communication and websites. They wish to share in a social emancipation process that can change them from simple consumers into energy producers, and overall, into those who spread the culture of sustainability and who live according to biosustainability geoethical principles.

Naturalife experiments and proposes new energy production technologies to the partners at extremely competitive prices. The selected products are tested within the Park, and if they show a good relationship in terms of duration, quality and price, they are proposed to the final consumers, with reductions in the costs that are estimated at up to $40 \%$, in comparison to market prices. A reserved internet site makes the booking of selected products possible. Once the pre-arranged quantity has been reached, these become real orders with exceptional cost reductions.

Moreover, the Park promotes a lot of study and search activities that are managed by open working groups. The major themes are: technology, education and popularization, communication, computer science and telecommunications, agriculture, new economy, mobility, energy efficiency, health, water management, and biohousebuilding and construction, among others. Today, anyone who joins Naturalife becomes an 'owner' of the Park, and can participate in thematic groups and enjoy the same advantages as the founders. The goal of the cooperative is to reach 50,000 partners within three years.

The first public presentation of Naturalife was on November 19, 2011, in Verona, during the 'Sustainable Society' symposium organized by the Zeitgeist Movement of Verona. This Movement includes around 500,000 people, and it is a system in which man's survival is based on the reduction of technology and economic demands.

Today, the Park has become a shared ownership with a participatory management. Above all, it constitutes the opportunity for anyone to recognize his/herself as an 'energy agent' of an open social system. A system that organizes, modifies and develops itself through actual geoethics: to compare, experiment, and democratically negotiate some good practices for the sustainability of our Planet. Naturalife is an interesting example of the generative process, in which rather than doggedly pursuing a predetermined objective, the actors "look for directions and values that are inherent in the means available" [Bateson 2000], including communication networks and the methodologies of social participation. The new community members focus their attentions on the effects of actions and relationships, rather than on ways to reach a predefined goal. They gather the transformation strength of every action, and learn to accept the uncertainty, the unforeseen event, and the fate, as factors of innovation and creation.

In this perspective, the experience provided by the Park is an interesting object of observation for its green ethics, which are not simply expressed as a behavioral code. For the Naturalife community, ecoethics is a practice, a social, democratic, responsible, and contextual trial in the search for sustainability [Walsh Stoddard and Grant, 2003].

\section{The Naturalife community: the route of identification}

As the Park of Renewable Energy project has come to the light, the promoters have encouraged open debate. At once, this invitation started a social trial, with a particular ethical character: to negotiate the meanings and values by which the stakeholders can recognize themselves as members of a community that promotes sustainable energy systems. The authors of this article have monitored the construction process of the Naturalife community since the beginning, and they have reported that many founding concepts have become focused. These are the following:

- The Park community constitutes the widespread body of the system: the network of partners produces, consumes and spreads all aspects of renewable energy, including intellectual and ethical ones, to reduce their impact on the global environmental, and to improve the quality of life of communities.

- The decisional faculty of the partners is intentionally participatory and negotiated, and it represents the collective mind and feeds the self-regulation process of the same system.

- The Park system constantly organizes, frees and extends itself in the directions for the best quality of life, through reduction of environmental impact, consumption, and costs, abandonment of classical energy sources, promotion of a new of lifestyle, and use and diffusion of daily ecosustainable products of consumption.

- All of the partners share the pragmatic exercise in ethics. When a decision must be taken, they promote negotiation processes that deal with all of the contextual factors in the game: human priority needs, economic and human resources, technological opportunities, and judicial-normative possibilities, among others. The debaters try to converge towards the best possible solution, while respecting the principles that govern sustainable social systems and the necessary conditions for a better future. Finally, the 'best possible solution' will come out: it will be the one shared by the greater part of the community.

- Communication, especially of decisional and managerial aims, inside and outside of Naturalife, is guaranteed by the internet, with computer platforms and social networks allowing participants to interact, both in a passive form (e.g. to receive news, information, invitations to social activities) and in an active form (e.g. to spread 
knowledge, to take part in debates, to vote on proposals).

- The widespread Naturalife community adopts the judicial form of the cooperative, to be able to channel the annual membership fees and others resources into search projects, into activities for the promotion and expansion of the social system, and into Park management.

Moreover, the identification of the cooperative procedure of the Naturalife mission has produced other interesting effects at the level of the partners' awareness. While the founding principles were forming, at the same time, the participants focused on their own profiles as members of an ecoethical community, so that they identified and shared some distinguishing characteristics, including:

- Naturalife members constitute the first and principal energy source of the system, and they sustain the existence of the Park by devoting economic and intellectual resources to it;

- Naturalife members collectively decide the lines of experimentation on the priority needs of the majority; they choose to whom to submit any search for new energy applications or sources;

- Naturalife members constitute the first group testing new sustainable energy solutions; they use global consultation with the Park experts to reduce their daily consumption and to use alternative energy sources;

- Naturalife members reciprocally increase their own competences around the use of new technologies;

- Naturalife members form a large buying group (gruppo di acquisto) of tecnological systems for the production of renewable energy;

- Naturalife members constitute a community with good know-how, to propose local and national norms on these matters;

- Naturalife members are spreaders of the sustainability culture, and vehicles of contamination of the current ecological needs;

- Naturalife members are agents for the transformation of anti-ecological ways of life, mental attitudes, and behaviors;

- Naturalife members form a community that can empower itself towards new, more sustainable, forms of economic and social organization.

\section{Conclusions}

The social experience that is promoted by the Park of Renewable Energy represents an interesting example of an ethical ecological approach to the environmental question, especially relating to alternative energy sources. Even if international debate appears to be far from solving the energy problem, this global challenge can become an opportunity for the human community to question the ways in which our primary needs are defined and the resources - not only the natural ones - are consumed on our
Planet. On the one hand, answering such questions requires a comparison between what is scientifically possible and what is socially necessary. On the other hand, the way of thinking and the lifestyle of modern urban man need to be revised in the direction of more responsible sustainable behavior. Above all, we cannot effectively face these aspects unless we are willing to change ourselves by practicing the ethics of sharing and cooperation.

In this perspective, the Naturalife association provides a good opportunity for anyone who wants to experiment with newer forms of social participation, to learn a lot about reduction in consumption and about home-made energy sources, and to practice the ethics of sustainability.

\section{References}

Bateson, G. (2000). Steps to an Ecology of Mind, Chicago/ London, University of Chicago Press.

Galimberti, U. (2000). Psiche e techne. L'uomo nell'età della tecnica, Milano, Feltrinelli Editore.

Morin, E. (1999). La tête bien faite: repenser la réforme, réformer la pensée, Paris, Éditions du Seuil.

Walsh Stoddard, E., and H.C. Grant (2003). Peripheral Visions: Towards a Geoethics of Citizenship, Lib. Educ., 89, 44-51.

*Corresponding author: Patrizia Sibi, Università di Viterbo, Dipartimento di Ecologia e Scienze Biologiche (DEB), Centro di Educazione Ambientale, Viterbo, Italy; email: sibipat@libero.it.

(C) 2012 by the Istituto Nazionale di Geofisica e Vulcanologia. All rights reserved. 